\title{
No Evidence of Failure of the Renin-Angiotensin System in Focal Glomerulosclerosis in Man
}

\begin{tabular}{|l|l|l|}
\hline C.P. & Charles P. & Swainson \\
\hline M.G. & Gary & Nicholls \\
\hline E.A. & Eric A. & Espiner \\
\hline
\end{tabular}

Department of Medicine, Christchurch Clinical School, Christchurch Hospital, and Department of Endocrinology, Princess Margaret Hospital, Christchurch, New Zealand

Dr. C.P. Swainson, Department of Nephrology, Christchurch Hospital, Christchurch (New Zealand)

\section{Dear Sir,}

Focal glomerulosclerosis (FGS) in man is usually accompanied by striking hyaline thickening in arteriolar walls even when the blood pressure and glomerular filtration rate are normal $[1,2]$. It is not known whether this arteriolar change is important in the pathogenesis of the glomerular disease but similar changes are seen also in other lesions associated with the development of FGS, and particularly reflux nephropathy [3]. Rats which develop spontaneous FGS have been shown to have decreased plasma renin activity (PRA) and the PRA falls before histological lesions are evident [4]. We have investigated patients with FGS who have normal renal function and blood pressure to see whether any failure of the renin-angiotensin system can be demonstrated. We chose to use measurement of the PRA and aldosterone as suppression of the renin-angiotensin system (RAS) should be evident by a demonstration of low values during stimulation by upright body posture.

Methods

Seven patients ( 2 female, 5 male) volunteered for study. All had presented with proteinuria ( 4 with nephrotic syndrome) 3-5 years

earlier. All had undergone renal biopsy which demonstrated the classical changes of FGS. None was taking medication and they were tested as outpatients on their normal diet. Subjects were asked to make a 24 hour urine collection at home on the day before the test. At 10.00 am, after they had been ambulant for at least $20 \mathrm{~min}$, a venous blood sample was taken for PRA, aldosterone, and electrolytes. The sitting blood pressure was measured after a further 15-min rest.

Urinary and plasma electrolytes, creatinine and albumin were assayed by standard laboratory techniques and PRA and aldosterone by radioimmunoassays [5,

6]. The creatinine clearance (CCr) was calculated but not corrected for surface area.

Results and Discussion

The results are shown in table I. The blood pressure was less than 140/90 in all subjectes. Only 1 subject had a slightly low plasma aldosterone (99 pmol/1) and PRA $(0.36 \mathrm{nmol} / \mathrm{l} / \mathrm{h})$; all other subjects had values within the normal range established in healthy volunteers under identical conditions. None of the subjects were sodium depleted.

In conclusion, these patients with established FGS showed no evidence to support suppression of the RAS although these data do not exclude an intrarenal defect in angiotensin II production. It would appear unlikely that suppression of the RAS is important in the pathogenesis of FGS in man.

Table I. Renin-angiotensin system in FGS

\section{6}

\section{Swainson/Nicholls/Espiner}

\section{References}

Hyman, L.R.; Burkholder, P.M.: Focal sclerosing glomerulo-nephropathy with segmental hyalinosis: a clinicopathologic analysis. Lab. Invest. 25:533544(1973).

Jenis, E.H.; Teichman, S.; Briggs, W.A.; Sandier, P.; Hollerman, C.E.; Calcagno, P.L.; Kneiser, M.R.; Jensen, G.E.; Valenski, J.E.: Focal segmental glomerulosclerosis. Am. J. Med. 57: 695-705 (1974).

Kincaid, Smith, P.: Glomerular lesions in atrophic pyelonephritis and reñux nephropathy. Kidney int. S:S81-S83 (1975).

Magro, A.M.; Rudolfski, U.H.: Plasma renin activity decrease precedes spontaneous focal glomerulosclerosis in ageing rats. Nephron 57/245-253 (1982).

Dunn, P.J.; Espiner, E.A.: Outpatient screening tests for primary aldosteronism. Aust. N.Z. J. Med. 6:131-135 (1976). 